Full length research article

\section{SUSCEPTIBILITY OF SOME SPECIES OF MOSQUITOES TO PERMETHRIN PYRETHROID IN ZARIA NIGERIA.}

\author{
*I. S. Ndams ${ }^{1}$, K. M. Laila ${ }^{1}$ and Z. Tukur²
}

\author{
${ }^{1}$ Department of Biological Sciences \\ Ahmadu Bello University Zaria, Nigeria \\ ${ }^{2}$ Department of Biological Sciences \\ Bayero University, Kano, Nigeria \\ ${ }^{*}$ (Corresponding author) \\ indams@yahoo.co.uk
}

\begin{abstract}
The susceptibility of Aedes aegypti Linnaeus 1762, Culex quinquefasciatus Say 1823 and Anopheles gambiae Giles 1902 was tested on $0.75 \%$ permethrin pyrethroid in the laboratory. All Larval and pupal stages of the mosquitoes were collected from different localities within Zaria, Nigeria and reared to adulthood in the laboratory. The adults that emerged were tested on $0.75 \%$ permethrin strips using WHO Standard Test Kit. Mortalities were recorded at five minutes interval for $1 \mathrm{hr}$ and maintained for 24hrs post-exposure on $7 \%$ sucrose solution after which a final mortality was recorded. The Knockdown times (KDT 50 and $\mathrm{KDT}_{95}$ ) were determined by Probit Analysis. $100 \%$ mortality was obtained for Ae. aegypti and CX. quinquefasciatus after $1 \mathrm{hr}$ and $24 \mathrm{hr}$ exposures, respectively, whereas An. gambiae recorded $92.11 \%$ and $90.91 \%$ mortalities after $1 \mathrm{hr}$ and $24 \mathrm{hr}$ exposure, respectively. The KDT 50 and $\mathrm{KDT}_{95}$ did not differ significantly $(P>0.05)$ between Ae. aegypti and $C x$. quinquefasciatus but differed significantly $(P<0.05)$ with $A n$. gambiae. The study shows that $A$ e. aegypti and $C$. quinquefasciatus are susceptible to permethrin whereas An. gambiae is resistant to the insecticide in the area.
\end{abstract}

Key Words: Permethrin, Aedes aegypti, culex quiquefasciatus, Anopheles gambiae, resistance, control, pyrethroid, Nigeria.

\section{INTRODUCTION}

Resistance to pyrethroid insecticides by mosquitoes is becoming a major public health issue in West Africa (Elissa et al. 1993; Chandre et al. 1999) where insecticide impregnated bednets are being promoted as a promising means of reducing malaria transmission (Bermejo \& Veeken, 1992; Carnevale et al. 1992). For treating bednets, pyrethroid compounds are the only insecticides recommended by the World Health Organisation (WHO). They are in general, very effective (with a strong excitorepellant effect on mosquitoes) yet having lower mammalian toxicity than organochlorine carbamate and organophosphate compounds and are less likely to bio-accummulate (Mittal et al. 1991).

Permethrin is a chemical widely used as an insecticide. It belongs to the family of chemicals called pyrethroids and functions as a neurotoxin affecting neuron membrane by slowing excess of important sodium ions. In agriculture, permethrin is mainly used on cotton, wheat and maize and is also used to kill parasites on chicken and other poultry. Its uses are controversial since as a broad spectrum chemical, it kills indiscriminately; as well as intended pests; it can harm beneficial insects including honey bees and small mammals such as mice. It is also used in health care to eradicate ectoparasites such as head lice and scabies and in industrial and domestic settings to control pests such as ants and termites (Wikkipedia 2006).

Mosquitoes are vectors of diseases. There are a few reported cases of the resistance of Culex, Aedes and Anopheles to chemical based compounds. However, there is little or no information that points to which of these genera of mosquitoes is resistant to permethrin pyrethroid. The paper reports on the susceptibility of the most abundant mosquitoes in the study area to permethrin pyrethroid. The results are discussed with respect to control strategy of mosquitoes of public health in the area and Nigeria in general.

\section{MATERIALS AND METHODS}

Larval and pupal stages of four mosquitoes species were collected from breeding sites within Samaru and environs in Zaria. Aedes aegypti Linnaeus 1762 was collected from the Ahmadu Bello University (ABU) fountain, Culex quinquefasciatus Say 1823 was collected from pools of stagnant water in Samaru village and Areas A residential area of ABU, whereas, Anopheles gambiae Giles 1902 was collected from a breeding site near Layin Zomo. All the immature stages were reared to adulthood in the laboratory, during which they were fed with fine powder of fish flakes. The susceptibility test was done as soon as the adults emerged using WHO (1998) Standard Test Kit and procedure. A maximum of 100 female mosquitoes in four replicates for each species were tested.

Accordingly, $0.75 \%$ permethrin impregnated paper strips was introduced into 4 exposure tubes and rolled to line with the wall of the tube and fastened into position by a wire clip. The control was lined with plain sheet of paper. A pre-test was performed by carefully introducing 25 female mosquitoes of each species into the four holding tubes with an aspirator and allowed to stand for ten minutes. After which the mosquitoes were transferred into the exposure tubes through a hole on the lid that separated the holding tube and the exposure. The exposure tubes were then set upright with the screen-end up and allowed to stand for 1 hour. Records of mortalities were taken at 5 minutes interval. The mosquitoes were carefully transferred back to the holding tubes and kept for 24 hours during which they were fed with $7 \%$ sucrose solution. Records of final mortality were taken after 24 hours. All the dead mosquitoes were removed from the holding tubes and identified using morphological keys of (Gillet 1972; Gillies \& Coetzee 1987; Service 1980).

\section{DATA ANALYSIS}

Mortalities were expressed as percentages (Table 1) while $\mathrm{KDT}_{50}$ and $\mathrm{KDT}_{95}$ (Table 2) were determined by probit analysis.

\section{STATISTICAL ANALYSIS}

Analysis of Variance (ANOVA) was used to compare the mortalities between the mosquitoes species and Least Significant Difference (LSD) was used to separate the means. 


\section{RESULTS}

Four mosquito species were collected during the investigation. Of the 238 collected, Ae. aegypti and Cx. quinquefasciatus had $100(41.49 \%)$ each, while $38(15.77 \%)$ were An. gambiae. The 3 An. pretoriensis representing $1.24 \%$ of the catch encountered were excluded from the analysis.

The results obtained from the susceptibility tests with $0.75 \%$ permethrin are presented in Tables 1 and 2.
The result in table 1 shows the mean mortality of the mosquitoes (Ae. aegypti, Cx. quinquefasciatus and An. gambiae). It shows that the knock down time of 35 minutes with $100 \%$ mortality was achieved for Ae. aegypti and no mosquito survived after 24 hours post exposure.

Similarly, $100 \%$ mortalities was achieved for Cx. quinquefasciatus with a knockdown time of 30 minutes and all died after 24 hours exposure to the pyrethroid.

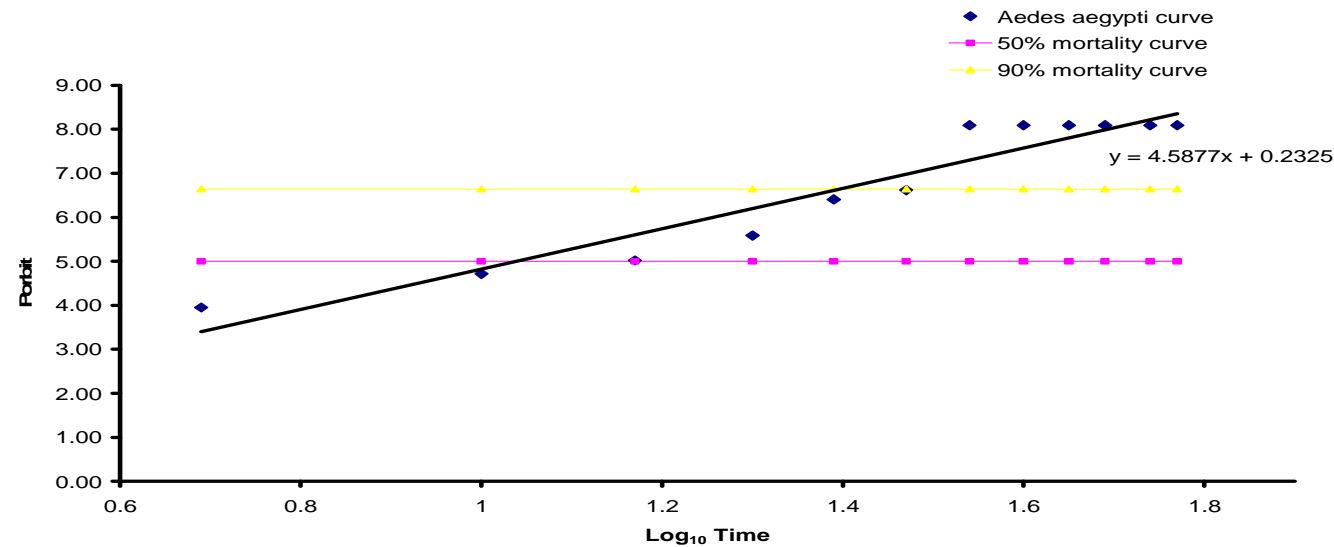

FIG.1: KDT $_{50}$ AND KDT KI $_{95}$ of AEDES AEGYPTI.

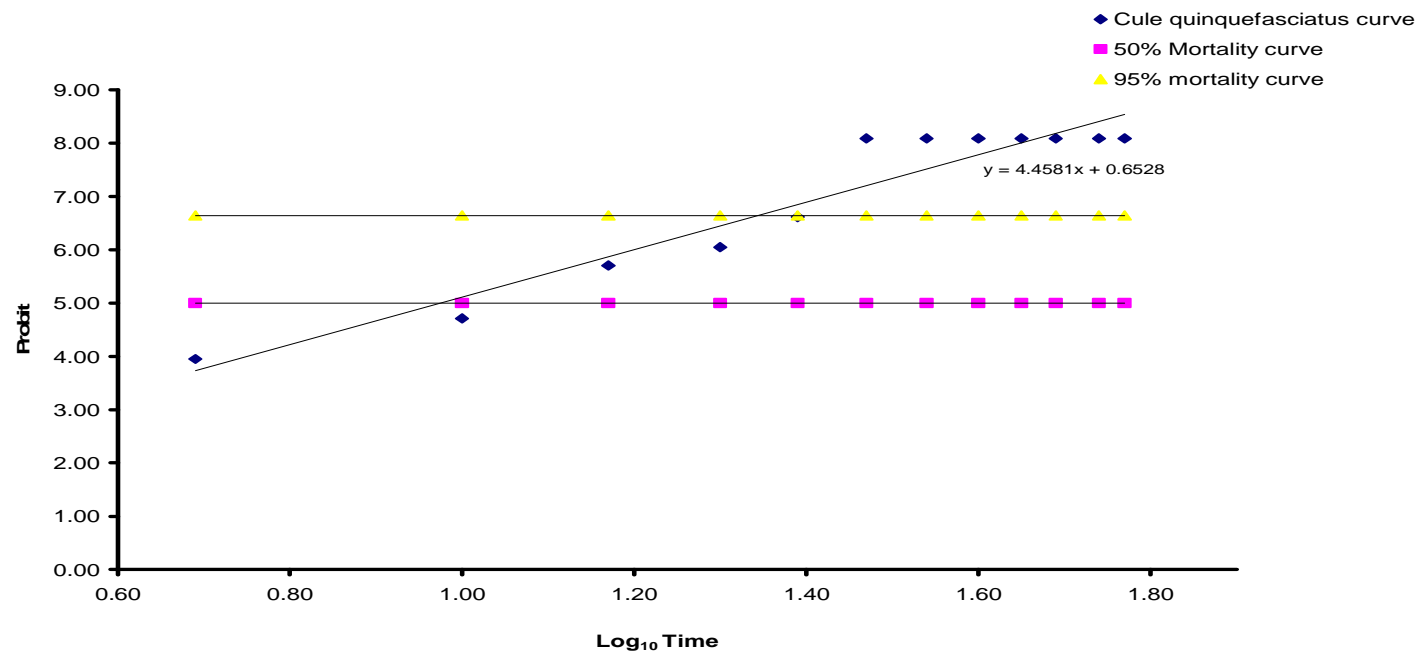

Fig 2: $\mathrm{KDT}_{50}$ AND $\mathrm{KDT}_{95}$ FOR C. QUINQUEFASCIATUS. 


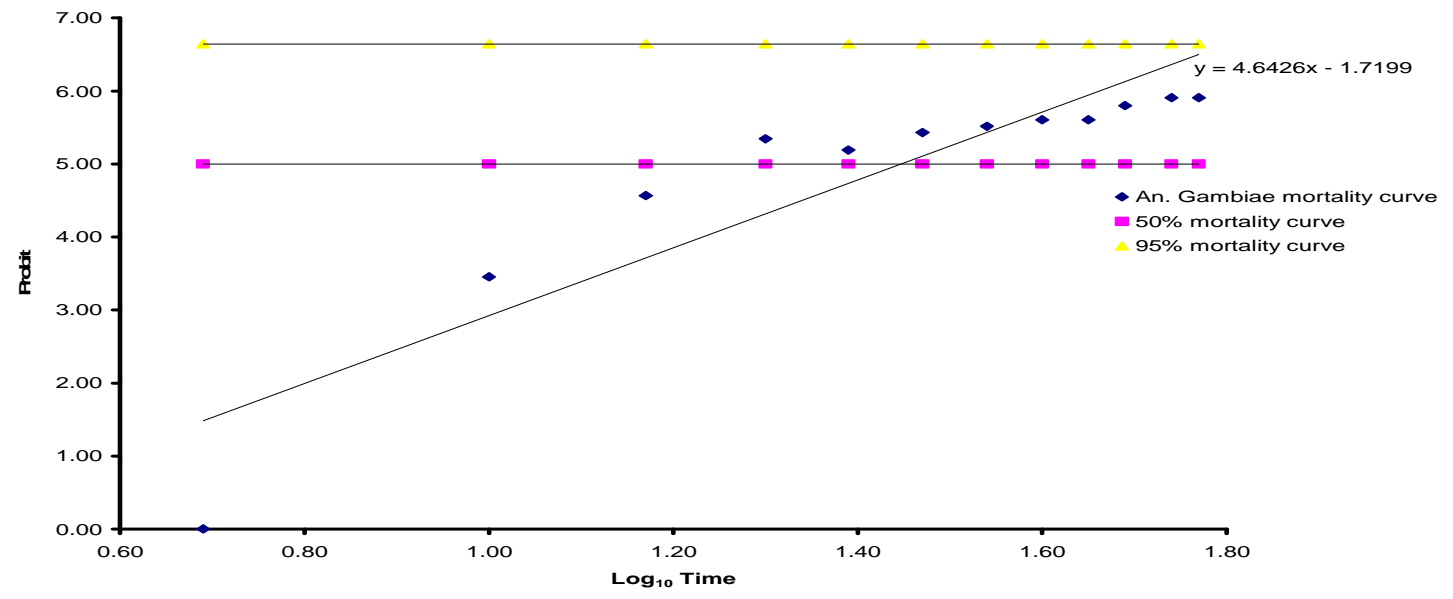

Fig 3: $K^{2} T_{50}$ AND KDT 95 FOR AN. GAMBIAE

There was no record of mortality in the control test. An. gambiae did not achieve 100\% during the 1 hour and 24 hours but $90.91 \%$ post exposure observation. Three (3) individuals survived after $24 \mathrm{hr}$ post exposure and were further maintained for 3 weeks after the test to confirmed resistance to the permethrin exposure. Comparing the mortalities caused by the permethrin exposure did not differ significantly between $A e$. aegypti and $C x$. quinquefasciatus $(P>0.05)$ but differed significantly between the two species and $A n$. gambiae $(P<0.05)$. The mortalities of 3 mosquitoes species differed significantly $(P<0.05)$ with the control test.

Figures 1-3 shows the determination of the $\mathrm{KDT}_{50}$ and $\mathrm{KDT}_{95}$ and the result is presented in Table 2 where the mortalities $24 \mathrm{hr}$ post exposure were $100 \%$ for Ae. aegypti and Cx. quinquefasciatus while $90.91 \%$ mortality was recorded for Anopheles gambiae sl which differed significantly $(P<0.05)$ from the other two species. However, the $\mathrm{KDT}_{50}$ and $\mathrm{KDT}_{95}$ as for $A e$. aegypti and $C x$. quinquefasciatus are not significantly different $(P>0.05)$ but differed significantly $(P<0.05)$ with $A n$. gambiae sl

\section{DISCUSSION}

The investigation revealed that 3 of the 4 species of mosquitoes are prevalent in the study area and was used for the susceptibility tests. They included Ae. aegypti, Cx. quinquefasciatus and An. gambiae s.l. whose prevalences and abundances have been reported (Hanney 1958; Adebote et al. 2006). An. pretoriensis being reported for the first time in the area was excluded from further analysis because of the small number caught. Further studies on this species are being suggested.

In this study, species are defined as susceptible if they achieve $95 \%$ mortality or more and they are defined as resistant if they show less than 95\% mortality after exposure to permethrin pyrethroid (WHO 1998; Chandre et al. 1999). Ae. aegypti and
Cx. quinquefasciatus are susceptible to permethrin having achieved $100 \%$ mortality respectively, during the 24 hours post exposure, confirming the knock down time effects of 35 minutes for Ae. aegypti and 20-30 minutes for Cx. quinquefasciatus during which the permethrin pyrethroid caused $100 \%$ mortalities, respectively, during the 1 hour bioassay period.

Molta (1979) reported $100 \%$ susceptibility of $C x$. pipiens fatigans and $A e$. aegypti and suggest that permethrin pyrethroid, though a target insecticide treated bed-nets (ITNs) insecticide against malaria vectors is effective against other vectors of public heath importance. An. gambiae proved resistance to permethrin pyrethroid having scored $90.91 \%$ mortality after 24 hours post exposure and $92.11 \%$ mortality observed during the 1 hour test. Furthermore, 3 An. gambiae survived after the 24 hour post exposure test which were kept for 2 weeks and fed with $7 \%$ sucrose solution. All these results suggest that the An. gambiae sl. tested was resistant to permethrin pyrethroid. Awolola et al. (2002) reported resistance of An. gambiae molecular forms collected from Ikara, a distance of $150 \mathrm{~km}$ east of Zaria where the current study was conducted. The resistance reported for An. gambiae sl in this investigation suggest that permethrin which is a pyrethroid of choice for ITNs in Nigeria and other endemic countries is no longer effective against the malaria vector in the study area. This calls for the use of an alternative pyrethroid or other organophosphates or organochlorine in treating ITNs either single or in combination.

Comparatively, the KDT95 of $\mathrm{Cx}$. quinquefasciatus and $\mathrm{Ae}$. aegypti did not differ significantly $(P>0.05)$ but it does $(P<0.05)$ with An. gambiae sl suggesting that the behaviours of the mosquito species in the study area may account for the lack of development of resistance to the insecticide. 
TABLE 1. MORTALITIES OF MOSQUITO SPECIES AFTER 1HR EXPOSURE TO 0.75\% PERMETHRIN PYRETHROID

\begin{tabular}{lcccccccccccccccc}
\hline Control & 0.00 & 0.00 & 0.00 & 0.00 & 0.00 & 0.00 & 0.00 & 0.00 & 0.00 & 0.00 & 0.00 & 0.00 & $0.00^{\mathrm{a}}$ \\
Ae. aegypti & 14.67 & 38.67 & 50.67 & 72.00 & 92.00 & 94.67 & 100.00 & 100.00 & 100.00 & 100.00 & 100.00 & 100.00 & $84.11^{\mathrm{b}}$ \\
C. quinquefasiatus & 14.67 & 38.67 & 76.00 & 85.33 & 94.67 & 100.00 & 100.00 & 100.00 & 100.00 & 100.00 & 100.00 & 100.00 & $80.22^{\mathrm{b}}$ \\
An. gambiae I & 0.00 & 6.06 & 33.33 & 63.64 & 57.58 & 66.67 & 69.70 & 72.73 & 72.73 & 78.79 & 90.91 & 90.91 & $57.07^{\mathrm{c}}$
\end{tabular}

$F=28.9886, F_{\text {critical }}=2.8165, P=0.016797$, significant: $L S D=10.187$

means with same letters are not significantly different

TABLE 2. PERCENTAGE MORTALITY AFTER 24HOUR RECOVERY PERIOD AND KDT50 AND KDT95

AFTER 1HOUR EXPOSURE TO PERMETHRIN INSECTICIDE IN THE MOSQUITO SPECIES

\begin{tabular}{lccc}
\hline Species & $\begin{array}{l}\text { Mortality after } \\
24 \text { hours (\%) }\end{array}$ & KDT $_{50}$ & KDT $_{95}$ \\
\hline Ae. aegypti & 100 & $11^{\mathrm{a}}$ & $25^{\mathrm{a}}$ \\
C. quinquefasciatus & 100 & $9 \mathrm{9}$ & $22^{\mathrm{a}}$ \\
An. gambiae sl & 90.91 & $28^{\mathrm{b}}$ & $63^{\mathrm{b}}$ \\
\hline
\end{tabular}

Figures with same letters in columns are not significantly different $(P>0.05)$ 
Aedes and Culex are mostly outdoor feeders and breeders whereas An. gambiae species is mostly found indoors in close association with human habitations. Similarly agricultural and domestic insecticide have not exerted enough pressure for the development of resistance in Culex and Aedes but resulted in the development of resistance to permethrin in An. gambiae sl.

\section{ACKNOWLEDGEMENT}

The authors thank the laboratory staff of the Department of Biological Sciences, ABU Zaria for technical assistance.

\section{REFERENCES}

Adebote, D. A.; Oniye S. J.; Ndams I. S.\& Nache, M, K. 2006. The Breeding of mosquitoes in peridomestic containers and implications in yellow fever transmission in villages around Zaria, Northern Nigeria. Journal of Entomology, 3(2):180-188

Awolola, T. S.; Brooke, B. D.; Hunt, R. H.; \& Coetzee M. 2002. Resistance of the malaria vector Anopheles gambiae s.s to pyrethroid insecticides in South Western Nigeria. Annals of Tropical Medicine and Parasitology, 96:849-852.

Bermejo, A. \& Veeken, H. 1992. Bulletin of the World Health Organisation 70, 293-296.

Brogdon, W.G \& McAllister, J. C. 1998. Insecticide resistance and vector control. Emerging Infections diseases, 4(4):1-11.

Carnevale, P.; Bitsindou P.; Djomande, L. \& Robert, V. 1992. Transactions of the Royal Society of Tropical Medicine and Hygiene, 86, 362-364.

Chandre, F.; Darriet, F.; Manga, L.; Akogbeto, M.; Faye, O.; Mouchet J. \& Guillet, P. 1999. Status of pyrethroid resistance in Anopheles gambiae sl. Bulletin of the World Health Organisation, 77:230-234.
Elissa, N.; Mouchet, J.; Riviere, F.; Meunier, J. Y. \& Yao, K. 1993. Resistance of Anopheles gambiae s.s. to pyrethroids in Cote d'Ivoire. Annals de la societe Belge de Medecine Tropicale, 73:291-294

Gillet, J. D. 1972. Common African mosquitoes and their medical importance. John Swahi, London.

Gillies, M. T. \& Coetzee, M. 1987. A supplement to the Anophelinae of Africa South of the Sahara. Publications of the South African Institute for Medical Research No. 55 Johannesburg: South African Institute for Medical Research.

Hanney, P. N. 1958. The mosquitoes of Zaria province, northern Nigeria. Bulletin of Entomological Research, 51:145-171.

Mittal, P. K.; Adak, T.; \& Sharma, V. P. 1991. Acute toxicity of certain Organochloride, Organophosphate, synthetic pyrethroids and microbial insecticides to mosquito fish Gambusia affinis (Baird \& Girard). Indian Journal of Malariology, 28:167-170.

Molta, N.B. 1979. Preliminary investigation of the insecticidal properties of DBMT on the Mosquito Culex pipiens fatigans. B.Sc Project, Department of Biological Sciences, ABU Zaria, Nigeria.

Service, M. W. 1980. A guide to medical entomology. The Macmillan Press Ltd. London.

Wikkipedia, 2006. http://en.wikipedia.org/wiki/permethrin.

World Health Organisation (WHO) 1998. Test Procedures for Insecticide Resistance monitoring in Malaria Vectors, Bioefficacy and Persistence of Insecticides on treated surfaces. Document WHO/CDS/CPC/MAL/98.12. Geneva 